\title{
SPECTRUM OF OPTIC NEUROPATHIES PRESENTING IN NEURO- OPHTHALMOLOGY CLINIC AT AFIO
}

\author{
Umer Ijaz, Asad Habib, Hassan Sajjad Rathore, Muhammad Imran Sarwar Khan* \\ Armed Forces Institute of Ophthalmology/National University of Medical Sciences (NUMS) Rawalpindi Pakistan, *Combined Military \\ Hospital Abbottabad/National University of Medical Sciences (NUMS) Pakistan
}

\begin{abstract}
Objective: To study the spectrum of optic neuropathies in patient's presenting at AFIO Rawalpindi. Study Design: Descriptive study/retrospective study.

Place and Duration of Study: Armed Forces Institute of Ophthalmology, Rawalpindi, from Jan 2017 to Dec 2017. Methodology: Retrospective analysis of hospital record of patients coming to neuro-ophthalmic clinic of Armed Forces Institute of Ophthalmology (AFIO), Rawalpindi, from Jan to Dec 2017 was done. Only patients with clear final diagnosis of neurophthalmic disease were included. Those with vague diagnosis were excluded. Data was entered in SPSS version 22 and grouped into variables before analysis. Chi-square test was used for statistical analysis. The $p<0.05$ was considered significant.

Results: Forty-five patients were included in study including 33 (73.3\%) males and 12 (26.6\%) females. Mean age of patients was $41.64 \pm 17.74$ years. Patients were grouped into ischemic optic neuropathy $20 \%$, toxic optic neuropathies $20 \%$, compressive optic neuropathies $17.7 \%$, inflammatory optic neuropathies $11 \%$, neuroretinitis $6.7 \%$, hereditary optic neuropathies $6.7 \%$, multiple sclerosis (MS) related $4.4 \%$, neuromylitis optics spectrum (NMO-SD) related $4.4 \%$, traumatic optic neuropathies $4.4 \%$ and nutritional optic neuropathies $4.4 \%$. Deficiency of vitamin B12 and vitamin D was strongly associated with nutritional optic neuropathies while raised TLC was most common association with inflammatory optic neuropathies $(57.14 \%)$ and of neuroretinitis (66\%). Anti-tuberculosis drugs were most common cause of toxic optic neuropathies $(88.88 \%)$. Chi square test was used for statistical analysis and $p<0.05$ was considered significant.

Conclusion: Ischemic optic neuropathy is the most common presentation in our population according to our study. However, the cohort is a small one. Future studies with larger cohort are recommended.
\end{abstract}

Keywords: Ischemic optic neuropathy, Neuropathy, Optic neuritis, Pituitary tumor, Traumatic optic neuropathy. This is an Open Access article distributed under the terms of the Creative Commons Attribution License (http://creativecommons.org/licenses/by/4.0), which
permits unrestricted use, distribution, and reproduction in any medium, provided the original work is properly cited.

\section{INTRODUCTION}

Optic neuropathies (ON) share a significant burden on ophthalmologists OPD. They may present from loss of visual acuity and color vision problems to visual field defects. Compressive, nutritional and hereditary $\mathrm{ON}$ generally have a slow progressive course while ischemic, inflammatory and traumatic ON have a rapid presentation. Correct diagnosis in a neuro phthalmic OPD not only needs a careful history but also correct clinical methods and assessment. Comprehensive counseling sessions add to patient's satisfaction and helps regular follow-up.

Signs on slit lamp examination are also vari-

Correspondence: Dr Asad Habib, Ophthalmology Department, Armed Forces Institute of Ophthalmology, Rawalpindi Pakistan Received: 09 Feb 2019; revised received: 26 Jul 2019; accepted: 26 Aug 2019 able among the various etiologies of optic neuropathies. Optic disc swelling is seen in optic neuritis while reterobulbar optic neuritis is a general presenting feature in MS related ON. Children usually present with papillitis while optic disc palor is generrly seen in nutritional and hereditary cases. Compressive ON can present with optic disc swelling in early stage and disc pallor later on. Occasionally palor is seen in one eye while other eye has disc swelling (pseudofoster kennady syndrome).

Ischemic Optic neuropathy is associated with vascular risk factors such as hypertension, hyperlipidemia, smoking, diabetes mellitus, nocturnal hypotension, blood loss, obstructive sleep apnea and hypercoagulable disorders ${ }^{1,2}$. Steroid treatment in the acute phase has been recommended 
by some experts ${ }^{3}$. Blood flow through the short posterior ciliary arteries may be disturbed in these patients ${ }^{4}$. Structurally small optic discs are known risk factor ${ }^{5,6}$. Non arteritic anterior ischemic Optic neuropathy (NAAION) develops in partiular above 50 years and present with sudden altitudinal VF defect. Arteritic anterior ischemic Optic neuropathy (AAION) presents late with association with GCA. $3^{\text {rd }}, 4^{\text {th }}$ and $6^{\text {th }}$ nerve palsies can be congenital or acquired after trauma or ischemic secondary to diabetes and hypertension. Compressive causes generally include pituitary tumors and craniopharyngiomas. Benign intracranial hypertension $(\mathrm{BIH})$ is a separate entity which is a diagnosis of exclusion after other organic causes of raised intracranial pressure have been ruled out and common in obese females ${ }^{7}$.

Armed Forces Institute of Ophthalmology (AFIO) is a tertiary care hospital and recently started a dedicated Neuro-Ophthalmic clinic. To the best of our knowledge, literature search using pubmed and other search engines the subject topic is scarcely studied. Dhiman et al ${ }^{8}$, and Karti et $a{ }^{9}$, studied it in Indian and Turkish population respectively. However no such study is done so far in Pakistani population. The rationale of conducting this study to look at common presentations and signs in various Neuro-Ophthalmic conditions in our setup. Our study group is rather a small one. Further studies involving larger cohort and multicenter trials will be helpful.

\section{METHODOLOGY}

It's a descriptive study performed at AFIO Rawalpindi. Retrospective analysis of record of neurophthamic clinic was done for patients coming from Januaury to December 2017. Forty five patients with final clear neurophthamlic diagnosis were included in the study. Those with vague diagnosis were excluded. Prior permission from Ethics review committee was taken. Informed consent was obtained from patients. SPSS-22 and chi square test were used for statistical analysis. $p<0.05$ was considered significant.
All patients were assessed by one experienced neuro-ophthalmologist at our tertiary care hospital. Demographic details, age, gender, pattern of presentation, laterality, associated signs and symptoms and pattern of disc changes were recorded. Examination included vision, color vision (Ishihara's Pseudo Isochromatic Color Vision Chart), pupil examination, dilated fundus examination, retinal nerve fiber layer (RNFL) assessment by Optical Coherence Tomography (Topcon) and visual field analysis (Humphrey and Goldman VF analyzer). Patients with multiple diagnoses, who lost follow-up or having no specific confirmed diagnosis, were excluded from study.

\section{RESULTS}

The total of patients diagnosed with optic neuropathy during the study period were 45 including $33(73.3 \%)$ males and $12(26.6 \%)$ females. Mean age of patients was $41.64 \pm 17.74$ years. Patients were grouped into ischemic optic neuropathy (ON) $20 \%$, toxic ON $20 \%$, compressive ON $17.7 \%$ [pituitary tumor in 3, optic nerve glioma in 2, meningioma, craniopharyngiomas and meningeal carcinomatosis in 1 each], inflammatory $\mathrm{ON}$ $11 \%$, neuroretinitis $6.7 \%$, Hereditary ON 6.7\%, multiple sclerosis (MS) related $4.4 \%$, neuromylitis optics spectrum (NMO-SD) related $4.4 \%$, traumatic $\mathrm{ON} 4.4 \%$ and nutritional $\mathrm{ON} 4.4 \%$.

Out of 45 respondents, $38 \%$ had bilateral involvement at presentation or subsequently established bilateral involvement, while $62 \%$ had unilateral involvement. Bilateral involvement was present in nutritional $(100 \%)$, hereditary $(100 \%)$, toxic $(78 \%)$ and compressive etiology (62.5\%). Presence of painwas mainly seen in MS-related ON (100\%) and inflammatory ON (75\%). RAPD was present at the time of presentation in $51.11 \%$ of the patients (table-II). Disc pallor was present in patients with compressive, traumatic, nutritional and hereditary optic neuropathies. $88 \%$ of patients with ischemic etiology had sectoral optic disc swelling or pallor. In optic neuritis, however, optic discs were normal in $20 \%$ of cases. Disc Pallor was the presenting sign in $25 \%$ with toxic 
and $100 \%$ of patients with compressive, traumatic, nutritional and hereditary optic neuropathies (table-I). Degree of color vision defect in various optic neuropathies if given in table-II.

Table-I: Optic disc appearance, rapd and visual field defect in various optic neuropathies.

\begin{tabular}{l|c|c|c|c}
\hline & $\begin{array}{c}\text { Disc } \\
\text { Swelling } \\
(\mathbf{( \% )}\end{array}$ & $\begin{array}{c}\text { Disc } \\
\text { Pallor } \\
(\mathbf{\%})\end{array}$ & $\begin{array}{c}\text { RAPD } \\
\mathbf{( \% )}\end{array}$ & $\begin{array}{c}\text { VF } \\
\text { defect } \\
\mathbf{( \% )}\end{array}$ \\
\hline Ischemic & $2(22.22)$ & $6(66.66)$ & $4(44.4)$ & $6(66.6)$ \\
\hline Inflammatory & $4(80)$ & $3(60)$ & $5(100)$ & $2(43)$ \\
\hline NMO-SD & - & $1(50)$ & $2(100)$ & $1(50)$ \\
\hline Trauma & - & $2(100)$ & $1(50)$ & $2(100)$ \\
\hline Nutritional & - & $2(100)$ & - & $2(100)$ \\
\hline Hereditary & - & $3(100)$ & - & - \\
\hline Neuroretinitis & $3(100)$ & - & $3(100)$ & $2(66.66)$ \\
\hline Toxic & - & $2(25)$ & $1(11.1)$ & $8(89)$ \\
\hline Compressive & $1(12.5)$ & $8(100)$ & $5(62)$ & $4(50)$ \\
\hline MS & - & - & $2(100)$ & - \\
\hline
\end{tabular}

Table-II: Pattern of loss of color vision in various types of optic neuropathies.

\begin{tabular}{l|c|c|c}
$\mathbf{N}=\mathbf{4 5}$ & $\begin{array}{c}\text { Normal } \\
\mathbf{( \% )}\end{array}$ & $\begin{array}{c}\text { Mildly } \\
\text { Reduced } \\
\mathbf{( \% )}\end{array}$ & $\begin{array}{c}\text { Severely } \\
\text { Reduced } \\
\mathbf{( \% )}\end{array}$ \\
\hline Ischemic & $2(22)$ & $2(22)$ & $5(56)$ \\
\hline Inflammatory & - & $2(40)$ & $3(60)$ \\
\hline NMO-SD & - & $1(50)$ & $1(50)$ \\
\hline Nutritional & - & $1(50)$ & $1(50)$ \\
\hline Hereditary & - & $1(50)$ & $1(50)$ \\
\hline Neuroretinitis & $1(33)$ & - & $2(66)$ \\
\hline Toxic & - & $2(25)$ & $7(75)$ \\
\hline Compressive & - & - & $8(100)$ \\
\hline MS & - & $1(50)$ & $1(50)$ \\
\hline
\end{tabular}

Table-III: Distribution of various optic neuropathies in this study compared to other similar studies.

\begin{tabular}{l|c|c|c}
\hline & $\begin{array}{c}\text { This } \\
\text { Study } \mathbf{( \% )}\end{array}$ & $\begin{array}{c}\text { Karti } \text { et } \\
\text { al } \mathbf{( \% )}\end{array}$ & $\begin{array}{c}\text { Dhiman } \text { et } \\
\text { al } \mathbf{~ ( \% )}\end{array}$ \\
\hline Ischemic & 20 & 39.2 & 14.75 \\
\hline Inflammatory & 11.1 & 27.9 & 1.17 \\
\hline NMO-SD & 4.44 & 4.6 & - \\
\hline Trauma & 4.44 & 4.1 & 22.24 \\
\hline Nutritional & 4.44 & - & - \\
\hline Hereditary & 6.7 & 1.25 & 7.9 \\
\hline Neuroretinitis & 6.7 & - & 11.35 \\
\hline Toxic & 20 & 3.75 & 7.9 \\
\hline Compressive & 17.7 & 2.5 & 20 \\
\hline MS & 4.44 & 16.7 & 14.05 \\
\hline
\end{tabular}

About $62.5 \%$ of patients with compressive lesions had both eyes involved. $80 \%$ of bilateral involved patients have bilateral disc pallor. One patient of compressive $\mathrm{ON}$ has disc swelling in one eye and atrophic disc in other (pseudo foster Kennedy syndrome) $58 \%$ of patients presented with some sort of visual field defect, central and paracentral being most common $(38.5 \%)$. As far as pattern of visual field defect is concerned, altitudinal VF defect was most common in ischemic optic neuropathy figure while toxic and nutritional had central, paracentral and centrocecal VF defects.

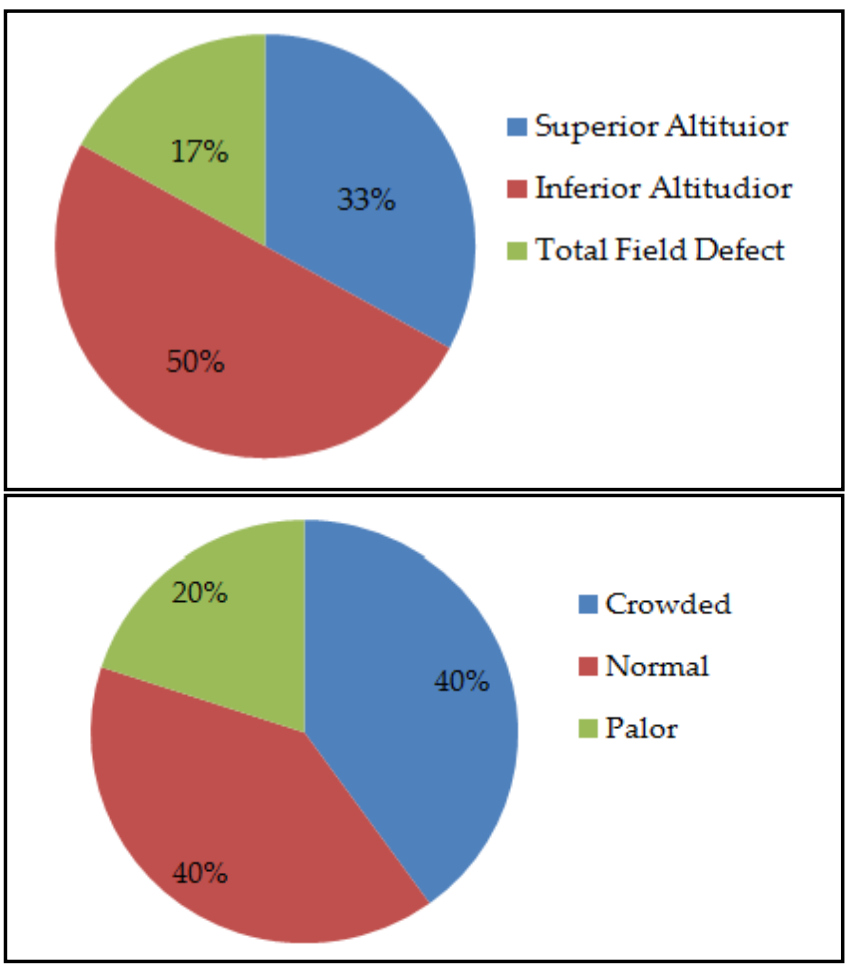

Figure: Common visual field defect and features of other eye in anterior ischemic optic neuropathies (\%).

Deficiency of vitamin B12 and vitamin D strongly associated with nutritional $\mathrm{ON}$ while raised TLC was most common association with inflammatory ON (57.14\%) and of neuroretinitis (66\%). Anti-tuberculous drugswere most common cause of toxic optic neuropathies (88.88\%). $50 \%$ of NMO patients were seropositive for aquaporin.

Regarding the most common type of optic neuropathy from this data, ischemic; About 1/ 3rd patients presented early with disc swelling and in 2/3rd we had disc palor and a retrerograde diagnosis of ischemic optic neuropathy 
from careful history was made. In $75.5 \%$ patients had crowded discs in the other healthy eye. In $62.5 \%$ cases had RNFL defect with altitudional visual field defect. However we were unable to find any clinically significant relationship between these finding, probably because of small number of patients $(p>0.05)$.

Regarding the patients with ischemic optic neurapathy, the most common neurophthalmic condition presenting to clinic in our study, the most common visual field defect is superior altitudional. Crowded disc is the common but not statistically significant finding in the other eye of patients with ischemic optic neurapathy (chi square test $p>0.05$ ) (figure).

\section{DISCUSSION}

Genereally all optic neuropathies present with reduced or altered vision, color vision or visual field. The severity and preference of any one optic nerve function vary with the cause of disease. As per our literature search there is limited data available on the spectrum of optic neuropathies in Pakistani population. Optic nerve functions are affected in generally all types of optic neuropathies. It may present in the form of decreased visual acuity, contrast sensitivity, visual field or color vision. Proper detail history taking is the key to correct diagnosis. Onset of symptoms can be abrupt or lingered over several days or weeks. Traumatic, inflammatory and demyelinating optic neuritis generally has an abrupt onset $^{10,11}$, while other have slow progressive one. Visual field automated as well as Goldmann VF plus MRI brain and orbits with contrast enhancement especially with orbital fat suppression sequence are valuable tools in making correct diagnosis ${ }^{12,13}$.

Total patients in our study are 45 while that in Dhiman et al, and Karti et al, were 1020 and 240 respectively. The number of patients we received in neuro-ophthalmology clinic in the given time period was far less than expected. The main reason for this is probably a new setup and that most of the peripheral centers are unaware of this facility. A sizeable number of patients reached us at a time when the optic pallor/atrophy had completely set in, marking an irreversible stage. Need of early neuro-ophthalmic referral is thus suggested. Moreover, the percentages of different neuroophthalmic disease in our study is different from the similar studies (table-III) in the area probably referring to an under or overdiagnosis of these cases. A larger cohort will thus be helpful in future studies.

The incidence of traumatic optic neuropathy varies from $0.7 \%$ to $2.5 \%$ worldwide, with a comparative higher incidence reported from India14-18, while our study shows an incidence of $4.4 \%$ similar to Karti et al, (4.1\%). Ethambutol toxicity was found to be the most common cause of toxic neuropathy in study by Dhiman ${ }^{18}$. Our study also showed anti tuberculous treatment to be the major cause of it in $88.88 \%$ cases of toxic optic neuropathies.

As far as the treatment options are concerned they vary with the type of optic neuropathy. Role of steroids in traumatic ON or ischemic ON is widely studied in literature. Although previous studies didn't prove any effective role but later on researchers found out that it is effective if given early ${ }^{20}$. Karti et $a^{9}$, showed a promising role of steroids in cases of ischemic, MS related and NMOSD related ON however few authors didn't agree $^{21,22}$.

There are a lot of strong points of this study. Neuro-ophthalmological examination was performed on all patients extensively and thoroughly. Careful examination and exclusion of other causes of vision loss was also done. To the best of our knowledge, this was the first study to describe the entire spectrum of optic neuropathy in our country, which allowed us to compare different groups and sub-groups of optic neuropathies. In addition, in this study, we evaluated, examined, managed and followed the largest series of consecutive patients of optic neuropathies in our setting. However, there were somelimitations too. As the study was conducted in a tertiary care eye center, the patients selected were subject to referral bias and may not be the representative sample 
of the general population of the area. Also, being retrospective, the medical diagnoses were occasionally inferred by the histories of the patient, rather than by strict evaluation of patients.

\section{CONCLUSION}

This study is the first of its kind in Pakistan giving the breakup of neuro-ophthalmic patients reporting to a neuro-ophthalmic clinic in a tertiary care eye hospital. Ischemic optic neuropathy was the most common presentation in our population according to our study. However, the cohort was a smallerthan we were aiming for. Future studies with a larger cohort are recommended.

\section{CONFLICT OF INTEREST}

There is no conflict of interest to be declare by any authors.

\section{REFERENCES}

1. Hayreh SS. Ischemic optic neuropathy. Prog Retin Eye Res 2009; 28(1): 34-62.

2. Arnold AC. Pathogenesis of nonarteritic anterior ischemic optic neuropathy. J Neuroophthalmol 2003; 23(2): 157-63.

3. Hayreh SS. Ischemic optic neuropathies-where are we now. Graefes Arch Clin Exp Ophthalmol 2013; 251(8): 1873-84.

4. Kaup M, Plange N, Arend KO, Remky A. Retrobulbar haemodynamics in non-arteritic ischaemic optic neuorpathy. Br J Ophthalmol 2006; 90(1): 1350-53.

5. Tesser RA, Niendorf ER, Levin LA. The morphology of an infarct in nonarteritic anterior ischemic optic neuropathy. Ophthalmol 2003; 110(2): 2031-35.

6. Knox DL, Kerrison JB. Histopathologic studies of ischemic optic neuropathy. Trans Am Ophthalmol Soc 2000; 98(2): 203-22.

7. De Rivera Rodríguez FJ, Martinez-Sanchez P, de Luna OjedaRuiz J, Arpa-Gutierrez FJ, Barreiro-Tella P. Benign intracranial hypertension. History, clinical features and treatment in a series of 41 patients. Revista de Neurol 2003; 37(9): 801-05.

8. Dhiman R, Singh D, Gantayala SP, Ganesan VL, Sharma P, Saxena R. Neuro-Ophthalmology at a Tertiary Eye Care Centre in India. J Neuro-Ophthalmol North Am Neuro-Ophthalmol Soci 2018; 38(3): 308-11.

9. Karti O, Karti DT, Kilic İH, Gokcay F, Celebisoy N. Baseline demographics, clinical features, and treatment protocols of 240 patients with optic neuropathy: experiences from a neuroophthalmological clinic in the Aegean region of Turkey. Inter Ophthalmol 2019; 39(1): 155-66.

10. Miller NR, Newman NJ, Biousse V. Walsh \& Hoyt's Clinical Neuro-Ophthalmology: the essentials, $2^{\text {nd }}$ ed. Lippincott Williams \& Wilkins, Philadelphia 2007 [Internet]. https://www. amazon.com/Walsh-Hoyts-Clinical-Neuro-OphthalmologyEssentials/dp/ 0781763797.

11. Balcer LJ. Clinical practice. Optic neuritis. N Engl J Med 2006; 354(12): 1273-80.

12. Polman $\mathrm{CH}$, Reingold SC, Banwell B, Clanet M, Cohen JF, Filippi M. Diagnostic criteria for multiple sclerosis: 2010 revisions to the McDonald criteria. Ann Neurol 2011; 69(2): 292-302.

13. Steinsapir KD, Goldberg RA. Traumatic optic neuropathy: an evolving understanding. Am J Ophthalmol 2011; 151(6): 928-33.

14. Cockerham GC, Goodrich GL, Weichel ED, Orcutt JC, Rizzo JF, Bower KS, et al. Eye and visual function in traumaticbrain injury. J Rehabil Res Dev 2009; 46(6): 811-18.

15. Edmund J, Godtfredson E. Unilateral optic atrophy following head injury. Acta Ophthalmol (Copenh) 1963; 41(1): 693-97.

16. Nau HE, Gerhad L, Focrster M, Nahser HC, Reinhardt V, Joka T. Optic nerve trauma: clinical, electrophysiological andhis-tological remarks. Acta Neurochir (Wien) 1989; 89(2): 16-27.

17. Pirouzmand F. Epidemiological trends of traumatic optic nerve injuries in the largest Canadian adult trauma center. J Craniofac Surg 2012; 23(2): 516-20.

18. Sharma B, Gupta R, Anand R, Ingle R. Ocular manifestations ofhead injury and incidence of post-traumatic ocular motor nerveinvolvement in cases of head injury: a clinical review. Inter Ophthalmol 2014; 34(4): 893-00.

19. Global Tuberculosis Report. Annex 2: Country Profiles, 2015. Available at [Internet]: http://www.who.int/tb/publications/ global_reports/en/.

20. Radoi C, Garcia T, Brugniart C. Intravitreal triamcinolone injections in non-arteritic anterior ischemic optic neuropathy. Graefes Arch Clin Exp Ophthalmol 2014; 252(2): 339-45.

21. Piccolo L, Woodhall M, Tackley G, Jurynczyk M, Kong Y, Domingos J, et al. Isolated new onset atypical optic neuritis in the NMO clinic: serum antibodies, prognoses and diagnoses at follow-up. J Neurol 2016; 263(2): 370-79.

22. Petzold A, Plant GT, Chronic relapsing inflammatory optic neuropathy: asystematic review of 122 cases reported. J Neurol 2014; 261(1): 17-26. 